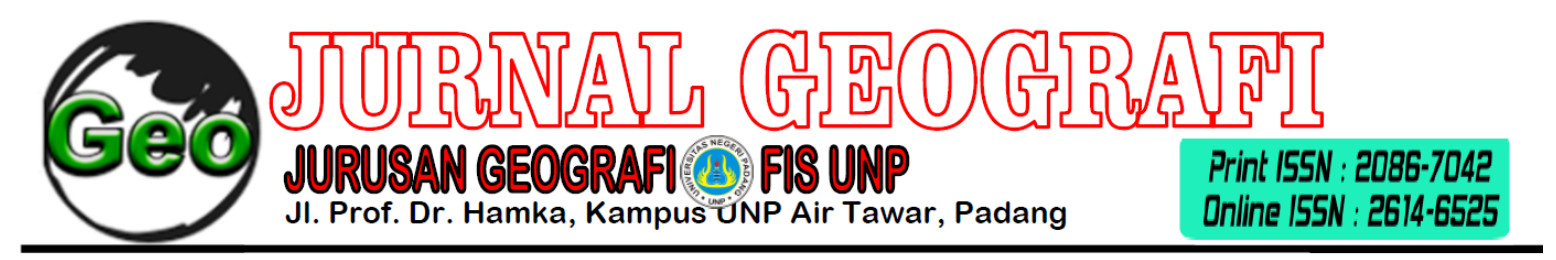

\title{
PENGARUH KAPASITAS TAMPUNG SUNGAI TERHADAP KETINGGIAN BANJIR BATANG SUMANI SOLOK
}

\author{
Helga Oktaviana ${ }^{1}$, Helfia Edial ${ }^{2}$, Widya Prarikeslan ${ }^{3}$ \\ ${ }^{1}$ Program Studi Geografi Fakultas Ilmu Sosial Universitas Negeri Padang \\ Email: helga.oktaviana94@gmail.com Telp.:082385719690
}

\begin{abstract}
ABSTRAK
Penelitian ini bertujuan untuk (1) Mengetahui debit banjir maksimum Batang Sumani, (2) Mengetahui debit Batang Sumani, (3) Mengetahui kapasitas tampung Batang Sumani, dan (4) Mengetahui pengaruh kapasitas tampung sungai terhadap banjir Batang Sumani. Jenis penelitian ini adalah deskriptif kuantitatif dengan teknik analisis data menggunakan metode rasional yang memanfaatkan data curah hujan, luas DAS dan penggunaan lahan. Hasil penelitian menunjukkan bahwa (1) Debit banjir maksimum Sub DAS Buluh 7,51 $\mathrm{m}^{3} / \mathrm{s}$, Sub DAS Lembang $48,01 \mathrm{~m}^{3} / \mathrm{s}$, Sub DAS Cupak $55,76 \mathrm{~m}^{3} / \mathrm{s}$ dan Sub DAS Lubuk Selasih $60,8 \mathrm{~m}^{3} / \mathrm{s}$. (2) Debit sungai Sub DAS Buluh $2,98 \mathrm{~m}^{3} / \mathrm{s}$, debit sungai Sub DAS Lembang $3,4 \mathrm{~m}^{3} / \mathrm{s}$, Debit sungai Sub DAS Cupak $3,36 \mathrm{~m}^{3} / \mathrm{s}$ dan debit sungai Sub DAS Lubuk Selasih 4,2 $\mathrm{m}^{3} / \mathrm{s}$. Total debit Batang Sumani 13,8 $\mathrm{m}^{3} / \mathrm{s}$. (3) Kapasitas tampung sungai Sub DAS Buluh 7,46 $\mathrm{m}^{3} / \mathrm{s}$, kapasitas Sub DAS Lembang 5,26 $\mathrm{m}^{3} / \mathrm{s}$, kapasitas Sub DAS Cupak $5,88 \mathrm{~m}^{3} / \mathrm{s}$ dan kapasitas Sub DAS Lubuk Selasih $6,96 \mathrm{~m}^{3} / \mathrm{s}$. Kapasitas tampung sungai rata-rata Batang Sumani $6,39 \mathrm{~m}^{3} / \mathrm{s}$. (4) Kapasitas tampung sungai terhadap banjir Batang Sumani memiliki pengaruh negatif sangat kuat. Setiap penambahan $1 \mathrm{~m}^{3} / \mathrm{s}$ kapasitas tampung sungai, ketinggian banjir akan berkurang 0,634 cm.
\end{abstract}

Kata Kunci : Debit Banjir Maksimum, Kapasitas Tampung Sungai

\section{ABSTRACT}

This study intends to (1) knowing the maximum flood debit of Sumani River, (2) knowing $t$ debit of Sumani River, (3) knowing the rivers capacity of Sumani River and (4) know the influence of river capacity on floood in Sumani River.this type of research was quantitative descriptive. Technique of data analysis using rational method by utilizing rainfall data, wide watershed and land use. The result showed that (1)maximum flood debit in Buluh sub watershed will become 7,51 $\mathrm{m}^{3} / \mathrm{s}$, Lembang sub watershed will become $48,01 \mathrm{~m}^{3} / \mathrm{s}$, Cupak sub watershed will become 55,76 $\mathrm{m}^{3} / \mathrm{s}$, and Lubuk Selasih sub watershed will become 60,6 $\mathrm{m}^{3} / \mathrm{s}$. (2) Rivers debit in Buluh sub watershed is $2,98 \mathrm{~m}^{3} / \mathrm{s}$, Lembang sub watershed is $3,4 \mathrm{~m}^{3} / \mathrm{s}$, Cupak sub watershed is $3,3 \mathrm{~m}^{3} / \mathrm{s}$ and Lubuk Selaih sub watershed is $8,89 \mathrm{~m}^{3} / \mathrm{s}$. Debit accumulation in Sumani watershed is $18,54 \mathrm{~m}^{3} / \mathrm{s}$ (3) Rivers capacity in Buluh sub watershed is $7,46 \mathrm{~m}^{3} / \mathrm{s}$, rivers capacity in Lembang sub watershed is $5,26 \mathrm{~m}^{3} / \mathrm{s}$. Rivers capacity in Cupak sub watershed is $5,88 \mathrm{~m}^{3} / \mathrm{s}$ and rivers capacity in Lubuk Selasih is $6,96 \mathrm{~m}^{3} / \mathrm{s}$. Average river capacity of Sumani river is $6,39 \mathrm{~m}^{3} / \mathrm{s}$ (4) river's capacity to flood height in Sumani river has a strong negative influence. Each addition of $1 \mathrm{~m}^{3} / \mathrm{s}$ of river capacity then the flood height will decrease 0,634.

Keywords : Maximum Flood Debit, River Capacity 


\section{PENDAHULUAN}

Manusia dan semua makhluk hidup membutuhkan air. Ketersediaan air dari segi kualitas maupun kuantitas mutlak diperlukan untuk kepentingan manusia. Air merupakan material yang membuat kehidupan terjadi di bumi. Semua organisme hidup tersusun dari sel-sel yang berisi air sedikitnya $60 \%$ dan aktivitas metaboliknya berada dalam larutan air (Enger dalam Kodoatie et al, 2002).

Pengelolaan air yang salah dapat menjadi bencana bagi kehidupan. Banjir dan kekeringan merupakan masalah alami yang langsung mempengaruhi hubungan antara ketersediaan dengan kebutuhan air. Air yang berlebihan pada suatu tempat akibat intensitas hujan yang tinggi dapat menjadi banjir dan genangan yang menimbulkan kerugian yang besar. Sebaliknya kekurangan air dapat memicu terjadinya bencana kekeringan (Darmanto, 2007).

Menurut UU Nomor 24 Tahun 2007 tentang penanggulangan bencana, bencana merupakan peristiwa atau rangkaian peristiwa yang mengancam dan mengganggu kehidupan dan penghidupan masyarakat yang disebabkan oleh faktor alam dan/atau faktor manusia sehingga mengakibatkan timbulnya korban jiwa, kerusakan lingkungan, kerugian harta benda dan dampak psikologis. Sedangkan Banjir adalah peristiwa yang terjadi ketika aliran air yang berlebihan merendam daratan.

Secara umum, banjir dapat diartikan sebagai suatu keadaan dimana tinggi muka air sungai (debit sungai) melebihi suatu batas yang ditetapkan oleh suatu kepentingan tertentu. Banjir merupakan hasil rusaknya kesetimbangan air (water balance) yang diakibatkan oleh berkurangnya nilai infiltrasi dan evapotranspirasi, sehingga nilai debit aliran permukaan (run off) menjadi lebih besar daripada kapasitas angkut debit air pada sistem drainase (alami maupun buatan). Nilai kapasitas angkut yang lebih kecil ini menyebabkan air meluap dari tanggul dan menggenangi daerah sekitarnya. Sungai dan saluran drainase dikatakan banjir apabila nilai debit rencananya hasil perhitungan menggunakan metode rasional lebih besar dari pada nilai kapasitas tampung maksimumnya (Megawati, 2005).

Kapasitas tampung sungai ditentukan dengan cara melakukan pengukuran debit dan penampang melintang sungai. Bila pengendapan terus terjadi, maka kapasitas tampung akan semakin berkurang, periode ulang dua tahun akan melimpah (Soewarno, 2014).

Publikasi Badan Nasional Penanggulangan Bencana (BNPB) tentang data perbandingan jumlah kejadian bencana di Indonesia sejak tahun 18152013 menyatakan bahwa bencana banjir berada pada urutan tertinggi dari seluruh jenis bencana yang terdapat di Indonesia. Bencana banjir tersebut meliputi banjir yang disebabkan oleh peran manusia baik secara langsung maupun secara tidak langsung (Widodo, 2014).

Masalah banjir di Indonesia sejak dulu sampai sekarang masih merupakan masalah yang belum dapat diselesaikan. Pada umumnya daerah yang selalu menjadi langganan banjir merupakan kotakota pantai dan kota yang berada di tepi sungai yang pada umumnya merupakan pusat-pusat aktivitas manusia. Penyebab banjir di Kota-Kota tersebut berasal dari sungai-sungai yang melalui daerah tersebut dan akibat banjir akibat pasang air laut.

Masalah banjir belum dapat diselesaikan secara tuntas, bahkan masalah 
tersebut justru diindikasikan semakin meningkat, baik dari sisi intensitas, frekuensi maupun sebarannya. Akibatnya dampak yang ditimbulkan juga semakin meningkat, faktor curah hujan yang tinggi merupakan salah satu indikator utama sebagai penyebab banjir (Widodo, 2014).

Perubahan tataguna lahan memberikan andil yang besar terhadap terjadinya peningkatan tajam debit sungai. Perubahan yang paling besar adalah apabila kawasan hutan itu dijadikan daerah beton/beraspal maka hujan yang turun semuanya akan mengalir dipermukaan dan tidak ada air hujan yang meresap kedalam tanah. Jika Daerah Aliran Sungai berupa persawahan kemudian dijadikan kawasan perindustrian, maka debit sungainya akan naik menjadi dua sampai tiga kali (Kodoatie et al, 2002).

Kabupaten dan Kota Solok tidak terlepas dari bencana banjir. Menurut sejarahnya (Koran Haluan, 2017) ratusan rumah dan ribuan hektar lahan pertanian pernah terendam banjir pada dua Nagari di Kecamatan Kubung Kabupaten Solok. Hujan yang terus mengguyur kabupaten Solok sejak sepekan terakhir membuat Batang Sumani yang membelah kawasan tersebut tak mampu lagi menampung debit air yang semakin meninggi.

Batang Sumani merupakan salah satu penyebab banjir di Kabupaten Solok dan Kota Solok. Batang Sumani merupakan sungai lintas kabupaten kota yang membelah Kota Solok dan Kabupaten Solok yang berada pada DAS Sumani.

Menurut artikel terbitan Fokusriau (2014), banjir Kabupaten Solok ditenggarai sebagai akibat penyempitan dan pendangkalan aliran sungai. Kondisi itu diperparah dengan kondisi badan sungai yang berkelok, terutama di Nagari
Koto Baru dan Salayo. Pada kawasan Batang Sumani, banjir bukan karena penggundulan hutan akibat illegal logging, tetapi lebih karena faktor pendangkalan dan penyempitan sungai.

\section{METODE PENELITIAN}

Berdasarkan masalah dan tujuan penelitian maka peneliti menggolongkan penelitian ini ke dalam penelitian deskriptif kuantitatif.

Jenis data yang digunakan adalah data primer dan data sekunder. Data primer berupa pengukuran debit sungai dan data sekunder berupa peta rupa bumi 1:50.000, peta penggunaan lahan 2015, data curah hujan 2003-2016 dan data debit sungai 2010-2016. Teknik penentuan sampel dalam penelitian ini adalah purposive sampling berdasarkan daerah dengan tingkat kerawanan banjir sedang dan tinggi serta lokasi pemantuan sungai DAS Sumani sehingga diperoleh empat sampel yaitu Kelurahan Koto Panjang, Nagari Koto Baru (dua sampel) dan Nagari Salayo.

Pengumpulan data yang dilakukan dalam penelitian ini adalah dengan menggunakan ArcGIS untuk menentukan batas DAS melalui pengolahan peta rupa bumi skala 1:50.000. Debit sungai ditentukan dengan observasi lapangan. Pengukuran debit sungai dilakukan dengan menggunakan metode pelampung.

Metode penelitian ini menggunakan metode rasional dalam memprediksi debit banjir dalam periode ulang tertentu. Metode rasional menggunakan data koefisien aliran, luas DAS dan intensitas curah hujan dalam menentukan potensi banjir suatu DAS dalam periode ulang tertentu.

Menentukan debit puncak $\left(Q_{\mathrm{p}}\right)$ atau debit banjir maksimum dengan 
menggunakan persamaan metode rasional (Kodoatie et al,2002)

$$
Q_{p}=0,0028 \text { C I } A
$$

Keterangan :

$\mathrm{Q}_{\mathrm{p}} \quad=$ Debit banjir maksimum

$\mathrm{C}=$ Koefisien aliran

I = Intensitas Curah Hujan ( $\mathrm{mm} / \mathrm{jam})$

A $=$ Luas Daerah Aliran Sungai $\left(\mathrm{km}^{2}\right)$

Menurut Asdak (2010) Debit sungai ditentukan dengan menggunakan persamaan berikut:

$$
Q=A \times V
$$

Keterangan :

$\mathrm{Q}=$ Debit sungai $\left(\mathrm{m}^{3} / \mathrm{s}\right)$

$\mathrm{C}=$ Kecepatan aliran sungai $(\mathrm{m} / \mathrm{s})$

A $\quad=$ Luas penampang DAS $\left(\mathrm{m}^{2}\right)$

Kapasitas tampung sungai dapat ditentukan dengan menggunakan metode yang sama dengan debit sungai tetapi menggunakan data tinggi sungai bukan tinggi muka air. Data tinggi sungai diperoleh dengan menghitung tinggi antara dasar sungai dengan daratan.

Pengaruh kapasitas tampung sungai terhadap banjir dilakukan dengan analisis statistik regresi linear sederhana. Kapasitas tampung sungai ditetapkan sebagai variabel bebas (independent variabel) yang dilambangkan dengan $X$. Sedangkan ketinggian banjir merupakan variabel terikat (dependent variabel) yang dilambangkan dengan Y. Data variabel terikat menggunakan data yang sudah ada berupa ketinggian banjir pada titik pengambilan sampel.

\section{HASIL DAN PEMBAHASAN \\ 1. Debit Banjir Maksimum DAS Sumani}

\section{a. Batas dan Luas DAS}

Batas DAS diukur pada peta topografi dengan melihat awal dari sebuah aliran sungai dengan mempertimbangkan titik ketinggian yang tinggi menuju titik ketinggian yang lebih rendah. DAS dibatasi pada punggungan bukit. Luas DAS diukur dengan memanfaatkan software ArcGIS 10.1.

Penelitian yang dilakukan menggunaan metode rasional meyebabkan DAS Sumani harus dibagi kedalam beberapa sub DAS yang lebih kecil agar hasil perhitungan lebih akurat. Pada penelitian ini, diambil sub DAS yang daerahnya sering mengalami banjir yaitu sub DAS yang melewati Kelurahan Koto Panjang, Nagari Salayo dan Nagari Koto Baru. Sub DAS yang diteliti yaitu Sub DAS Buluh, Sub DAS Lembang, Sub DAS Cupak serta Sub DAS Lubuk Selasih.

Berdasarkan pengolahan peta topografi skala 1:50.000 diperoleh Sub DAS yang ada pada DAS Sumani dengan luas masing-masing sebagai berikut:

Tabel 1. Luas DAS Sumani

\begin{tabular}{cc}
\hline Sub DAS & Luas $\left(\mathbf{k m}^{\mathbf{2}}\right)$ \\
\hline Buluh & 16 \\
\hline Lembang & 84 \\
\hline Cupak & 61 \\
\hline Lubuk Selasih & 128 \\
\hline \multicolumn{2}{c}{ Sumber : Data sekunder }
\end{tabular}

Sub DAS Lubuk Selasih merupakan Sub DAS terbesar dengan luas $128 \mathrm{~km}^{2}$ yang berada di daerah hulu DAS dengan aliran terbesar sebagai penyumbang debit banjir dan Sub DAS Buluh merupakan Sub DAS dengan luas terkecil yang berada pada bagian tengah das dengan luas 16 $\mathrm{km}^{2}$ 


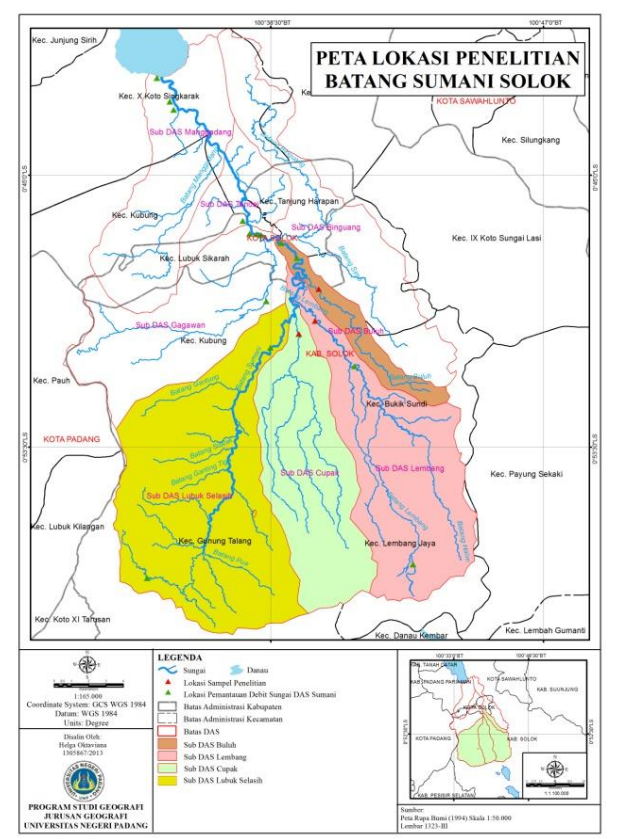

Gambar 1. Peta Batang Sumani Solok

\section{b. Koefisien Aliran}

Angka koefisien aliran merupakan salah satu indikator untuk menentukan apakah suatau DAS telah mengalami gangguan (fisik). Nilai koefisien aliran (C) disesuaikan dengan tabel koefisien aliran menurut US Forest Service dalam Asdak (2010). Menurut Asdak, jika pada DAS terdapat penggunaan lahan yang berbeda maka dicari nilai koefisien aliran rata-rata tertimbang.

Angka $\mathrm{C}$ berkisar antara 0 hingga 1 . Nilai $\mathrm{C}$ yang besar menunjukkan bahwa lebih banyak air hujan yang menjadi air larian. Semakin koefisien aliran mendekati nol, berarti menunjukkan semua air hujan terdistribusi menjadi air intersepsi.

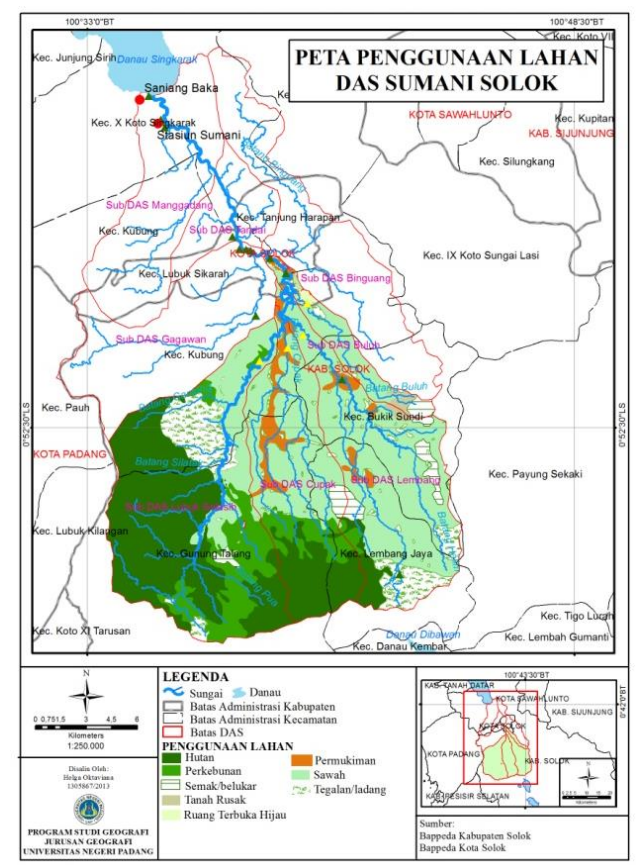

Gambar 2. Peta Penggunaan Lahan DAS Sumani 
Penggunaan lahan pada Sub DAS Buluh didominasi oleh sawah dengan luas $9,9 \mathrm{~km}^{2}$. Penggunaan lahan pada Sub DAS Lembang didominasi oleh sawah dengan luas $57,7 \mathrm{~km}^{2}$. Penggunaan lahan pada Sub DAS Cupak didominasi oleh sawah seluas $35,1 \mathrm{~km}^{2}$. Penggunaan lahan pada Sub DAS Lubuk Selasih didominasi oleh hutan sebesar 69,4 $\mathrm{km}^{2}$.
Nilai koefisien aliran pada Sub DAS Buluh dan Sub DAS Lembang sebesar 0,2, pada Sub DAS Cupak sebesar 0,19 dan pada Sub DAS Lubuk Selasih sebesar 0,12 . Nilai koefisien aliran pada ketiga Sub DAS tergolong hampir mendekati nol yang berarti banyak air hujan terdistribusi menjadi air infiltrasi terutama pada Sub DAS Lubuk Selasih yang berada pada bagian hulu DAS Sumani Solok.

Tabel 2. Nilai Koefisien Aliran Sub DAS Buluh, Sub DAS Lembang, Sub DAS Cupak dan Sub DAS Lubuk Selasih

\begin{tabular}{|c|c|c|c|c|c|c|c|c|}
\hline \multirow[t]{2}{*}{ Penggunaan Lahan } & \multicolumn{2}{|c|}{ Sub Das Buluh } & \multicolumn{2}{|c|}{$\begin{array}{l}\text { Sub Das } \\
\text { Lembang }\end{array}$} & \multicolumn{2}{|c|}{$\begin{array}{c}\text { Sub Das } \\
\text { Cupak }\end{array}$} & \multicolumn{2}{|c|}{$\begin{array}{c}\text { Sub DAS Lubuk } \\
\text { Selasih }\end{array}$} \\
\hline & $\overline{\mathrm{A}}$ & $\mathrm{C}$ & $\mathrm{A}$ & $\mathrm{C}$ & A & $\mathrm{C}$ & $\mathrm{A}$ & $\mathrm{C}$ \\
\hline Perkebunan & 0,1 & 0,2 & 1,2 & 0,2 & 6,9 & 0,19 & 19,8 & 0,12 \\
\hline Hutan & - & & 4,7 & & 9,6 & & 69,4 & \\
\hline Sawah & 9,9 & & 57,7 & & 35,1 & & 20,5 & \\
\hline Permukiman & 1,1 & & 4,1 & & 7,3 & & 2,2 & \\
\hline Tegalan/ Ladang & 0,6 & & 11,7 & & 1,2 & & 14,7 & \\
\hline Semak/ belukar & 1,6 & & 4,1 & & 1,6 & & 0,9 & \\
\hline Tanah Rusak & 1,4 & & 0,7 & & - & & - & \\
\hline Ruang Terbuka Hijau & 1,8 & & 0,2 & & - & & - & \\
\hline Kesehatan & 0,1 & & - & & - & & - & \\
\hline Pendidikan & 0,1 & & - & & - & & - & \\
\hline Pemakaman & 0,1 & & - & & - & & - & \\
\hline Perkantoran & 0,1 & & 0,1 & & - & & - & \\
\hline Militer & 0,1 & & - & & - & & - & \\
\hline Stasiun & 0,1 & & - & & - & & - & \\
\hline
\end{tabular}

Sumber: Pengolahan data sekunder (2012)

\section{c. Intensitas hujan}

Intensitas curah hujan dihitung berdasarkan besarnya curah hujan rencana menggunakan persamaan Mononobe (Megawati, 2005).

$$
I=\frac{R_{24}}{24}\left(\frac{24^{\frac{2}{3}}}{t_{c}}\right)
$$

Keterangan:

$\mathrm{I}=$ intensitas curah hujan ( $\mathrm{mm} / \mathrm{jam})$

$\mathrm{t}_{\mathrm{c}}=$ waktu konsentrasi (menit)
$\mathrm{R}_{24}=$ curah hujan maksimum dalam 24 jam (mm)

Waktu konsentrasi merupakan waktu yang dibutuhkan oleh air untuk mengalir mulai dari hulu sampai ke lokasi penelitian. Waktu konsentrasi dipengaruhi oleh ketinggian dan perbedaan jarak antara hulu dengan titik penelitian. Waktu konsentrasi dihitung dengan rumus Kirpich (Asdak, 2010). 


$$
t_{c}=0,0195 L^{0,77} \times S^{-0,385}
$$

Keterangan:

tc $=$ waktu konsentrasi (menit)

$\mathrm{L}=$ panjang maksimum aliran (m)

$\mathrm{S}=$ beda ketinggian antara titik pengamatan dengan lokasi terjauh pada DAS dibagi panjang maksimum aliran (m).
Panjang maksimum aliran diperoleh dengan mengukur panjang antara daerah hulu Sub DAS sampai kepada daerah yang dilakukan penelitian pada peta topografi 1:50.000. Beda ketinggian antara hulu sub DAS dengan lokasi yang diteliti dilihat pada peta topografi dan hasil pengamatan lapangan.

Tabel 3. Waktu konsentrasi Sub Das Buluh, Sub DAS Lembang, Sub DAS Cupak dan Sub DAS Lubuk Selasih

\begin{tabular}{lccc}
\hline \multicolumn{1}{c}{ Sub DAS } & L $(\mathrm{m})$ & $\mathrm{S}$ & $\begin{array}{c}\text { tc } \\
\text { (menit) }\end{array}$ \\
\hline Buluh & 10800 & 0,00963 & 148,62 \\
\hline Lembang & 18860 & 0,032 & 143,74 \\
\hline Cupak & 14200 & 0,042 & 103,9 \\
\hline Lubuk Selasih & 18076 & 0,027 & 147,19 \\
\hline \multicolumn{4}{c}{ Sumber : Pengolahan data sekunder (2012) }
\end{tabular}

Curah hujan area dihitung dengan menggunakan persamaan thiessen polygon dengan memanfaatkan luas DAS dan data curah hujan periode 2003-2016 serta stasiun pemantau hujan yang diperoleh dari Dinas Pengelolaan Sumber Daya Air (PSDA) Sumatera Barat, sehingga diperoleh besarnya curah hujan masingmasing sub DAS.

Jumlah stasiun yang mempengaruhi DAS Sumani berjumlah tiga buah stasiun yaitu Stasiun Stasiun Sumani, Stasiun Danau Diatas, dan Stasiun Ladang Padi. Lima stasiun tersebut masing-masing dihubungkan untuk memperoleh luas daerah pengaruh dari tiap stasiun. Dimana masing-masing stasiun mempunyai daerah pengaruh curah hujan yang dibentuk dengan garis-garis sumbu tegak lurus terhadap garis penghubung antara dua stasiun.

Stasiun Danau Diatas memiliki curah hujan 117, 65 - 396,35 mm/bulan. Stasiun Sumani memiliki curah hujan 104,6 282,52 mm/bulan yang merupakan curah hujan terendah dibandingkan sub DAS lainnya. Stasiun Ladang Padi memiliki curah hujan 184,15 - 401,39 mm/bulan dan merupakan curah hujan tertinggi dibandingkan sub DAS lain. 


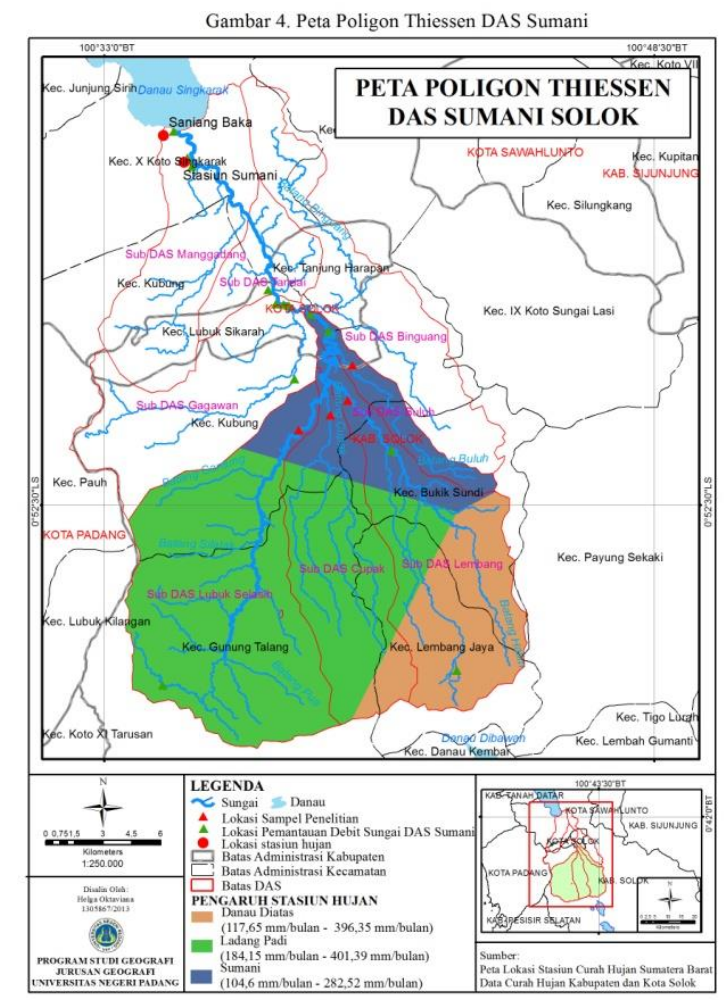

Gambar 3. Peta Poligon Thiessen DAS Sumani

Berdasarkan persamaan poligon DAS Sumani untuk masing-masing sub thiessen, diperoleh curah hujan rata-rata

DAS sebagai berikut:

Tabel 4. Curah Hujan Sub DAS Buluh, Sub DAS Lembang, Sub DAS Cupak dan Sub DAS Lubuk Selasih dengan Metode Poligon Thiessen

\begin{tabular}{lc}
\hline \multicolumn{1}{c}{ Sub DAS } & Rh (mm/bulan) \\
\hline Sub DAS Buluh & 167,90 \\
\hline Sub DAS Lembang & 197,63 \\
\hline Sub DAS Cupak & 252,01 \\
\hline Sub DAS Lubuk Selasih & 275,54
\end{tabular}

Sumber : Hasil pengolahan data sekunder (2003-2016)

Sebaran curah hujan dalam periode ulang tertentu ditentukan dengan menggunakan metode sebaran Gumbel Tipe I. Metode ini digunakan untuk memprediksi kemungkinan besarnya curah hujan dalam waktu tertentu. Persamaan metode sebagaran Gumbel Tipe I dalam Rifai (2008) sebagai berikut:

$$
X_{T}=\bar{X}+\frac{S}{S_{n}}\left(Y_{t}-Y_{n}\right)
$$

Keterangan:

$\bar{X}=$ curah hujan $(\mathrm{mm} / \mathrm{jam})$

$\mathrm{S}=$ standar deviasi

$S_{n}=$ Reduce standar deviation

$Y_{t}=$ Reduce mean

$Y_{n}=$ Reduce Variate 
Tabel 5. Distribusi Curah Hujan Sub DAS Buluh, Sub DAS Lembang,

Sub DAS Cupak dan Sub DAS Lubuk Selasih pada Periode Tertentu

\begin{tabular}{|c|c|c|c|c|c|c|c|c|}
\hline \multirow{2}{*}{$\begin{array}{c}\text { Periode } \\
\text { Ulang } \\
\text { (tahun) }\end{array}$} & \multicolumn{2}{|c|}{ Sub DAS Buluh } & \multicolumn{2}{|c|}{$\begin{array}{l}\text { Sub DAS } \\
\text { Lembang }\end{array}$} & \multicolumn{2}{|c|}{ Sub DAS Cupak } & \multicolumn{2}{|c|}{$\begin{array}{c}\text { Sub DAS Lubuk } \\
\text { Selasih }\end{array}$} \\
\hline & $\mathrm{X}$ & $\mathrm{Xt}$ & $\mathrm{X}$ & $\mathrm{Xt}$ & $\mathrm{X}$ & $\mathrm{Xt}$ & $\mathrm{X}$ & $\mathrm{Xt}$ \\
\hline 2 & 167,39 & 159,18 & 197,63 & 189,66 & 252,01 & 244,04 & 275,54 & 266,93 \\
\hline 5 & & 224,17 & & 252,73 & & 307,13 & & 335,12 \\
\hline 10 & & 267,21 & & 294,48 & & 348,9 & & 380,28 \\
\hline 25 & & 321,58 & & 347,24 & & 401,67 & & 437,32 \\
\hline 50 & & 361,92 & & 386,38 & & 440,82 & & 479,65 \\
\hline 100 & & 401,96 & & 425,23 & & 479,69 & & 521,66 \\
\hline
\end{tabular}

Sumber : Pengolahan data sekunder (2003-2016)

Sub DAS Cupak mempunyai pergerakan aliran air yang paling cepat dari hulu menuju hilir dengan waktu 1 jam 43 menit, sedangkan Sub DAS Buluh mempunyai pergerakan yang paling lambat dari hulu menuju hilir dengan waktu 2 jam 28 menit. Lambatnya pergerakan air pada Sub DAS Buluh dipengaruhi oleh panjang aliran yang singkat dan perbedaan tinggi yang kecil.

Intensitas curah hujan tertinggi pada ketiga sub DAS yang diteliti adalah pada sub DAS Cupak dengan intensitas sebesar $59,19 \mathrm{~mm} / \mathrm{jam}$ sedangkan yang terendah adalah pada sub DAS Buluh dengan intensitas sebesar $30,37 \mathrm{~mm} / \mathrm{jam}$.

Tabel 6. Intensitas Curah Hujan Sub DAS Buluh, Sub DAS Lembang,

Sub DAS Cupak dan Sub DAS Lubuh Selasih dalam Periode Tertentu

\begin{tabular}{ccccc}
\hline \multirow{2}{*}{$\begin{array}{c}\text { Periode } \\
\text { Ulang } \\
\text { Tahun) }\end{array}$} & $\begin{array}{c}\text { Sub DAS } \\
\text { Buluh }\end{array}$ & $\begin{array}{c}\text { Sub DAS } \\
\text { Lembang }\end{array}$ & $\begin{array}{c}\text { Sub DAS } \\
\text { Cupak }\end{array}$ & $\begin{array}{c}\text { Sub DAS } \\
\text { Lubuk Selasih }\end{array}$ \\
\hline 2 & 30,37 & 37,01 & 59,19 & 51,26 \\
\hline 5 & 42,77 & 49,31 & 74,49 & 64,36 \\
\hline 10 & 50,99 & 57,46 & 84,62 & 73,03 \\
\hline 25 & 61,36 & 67,75 & 97,42 & 83,99 \\
\hline 50 & 69,06 & 75,39 & 106,91 & 92,11 \\
\hline 100 & 76,7 & 82,97 & 116,34 & 100,18
\end{tabular}

Sumber : Pengolahan data sekunder 2003-2016

\section{d. Debit banjir maksimum}

Menentukan debit puncak $\left(\mathrm{Q}_{\mathrm{p}}\right)$ atau debit banjir maksimum dengan menggunakan persamaan metode rasional (Kodoatie et al,2002)

$$
Q_{p}=0,0028 \text { C I } A
$$

Keterangan :

$\mathrm{Q}_{\mathrm{p}}=$ debit banjir maksimum

$\mathrm{C}=$ Koefisien aliran

I = Intensitas Curah Hujan ( $\mathrm{mm} / \mathrm{jam})$

$\mathrm{A}=$ luas Daerah Aliran Sungai $\left(\mathrm{km}^{2}\right)$
Debit banjir yang bisa terjadi pada periode ulang 2 tahun kedepan (2019) pada Sub DAS Buluh adalah sebesar 7,51 $\mathrm{m}^{3} /$ detik. Debit banjir yang bisa terjadi pada periode ulang 2 tahun kedepan (2019) pada Sub DAS Lembang adalah sebesar $48,1 \mathrm{~m}^{3} /$ detik. Debit banjir yang bisa terjadi pada periode ulang 2 tahun kedepan (2019) pada Sub DAS Cupak adalah sebesar $55,76 \mathrm{~m}^{3} /$ detik dan pada Sub DAS Lubuk Selasih sebesar $60,8 \mathrm{~m}^{3} /$ detik. 
Tabel 7. Debit Banjir Maksimum Sub DAS Buluh, Sub DAS Lembang, Sub DAS Cupak dan Sub DAS Lubuk Selasih pada Periode Ulang Tertentu

\begin{tabular}{ccccc}
\hline $\begin{array}{c}\text { Periode } \\
\text { Ulang } \\
\text { (Tahun) }\end{array}$ & $\begin{array}{c}\text { Sub DAS } \\
\text { Buluh }\end{array}$ & $\begin{array}{c}\text { Sub DAS } \\
\text { Lembang }\end{array}$ & $\begin{array}{c}\text { Sub DAS } \\
\text { Cupak }\end{array}$ & $\begin{array}{c}\text { Sub DAS Lubuk } \\
\text { Selasih }\end{array}$ \\
\hline 2 & 7,51 & 48,01 & 55,76 & 60,8 \\
\hline 5 & 10,57 & 63,98 & 70,17 & 76,34 \\
\hline 10 & 12,6 & 74,55 & 79,72 & 86,62 \\
\hline 25 & 15,16 & 87,9 & 91,78 & 99,62 \\
\hline 50 & 17,06 & 97,81 & 100,72 & 109,26 \\
\hline 100 & 18,95 & 107,64 & 109,6 & 118,83 \\
\hline
\end{tabular}

Sumber: Pengolahan data sekunder (2003-2016)

\section{Debit Sungai}

Menurut Asdak (2010) Debit sungai ditentukan dengan menggunakan persamaan berikut:

$$
Q=A \times V
$$

Keterangan :

$\mathrm{Q}=$ debit sungai $\left(\mathrm{m}^{3} / \mathrm{s}\right)$

$\mathrm{C}=$ Kecepatan aliran sungai $(\mathrm{m} / \mathrm{s})$
$\mathrm{A}=$ luas penampang melintang DAS $\left(\mathrm{m}^{2}\right)$ Luas penampang melintang sungai dipengaruhi oleh lebar sungai dan tinggi muka air. Kecepatan aliran sungai diperoleh dengan menggunakan metode pelampung. Kecepatan aliran sungai merupakan hasil perbandingan antara jarak dengan kecepatan aliran.

Tabel 8. Debit Sungai Sub DAS Buluh, Sub DAS Lembang, dan Sub DAS Cupak

\begin{tabular}{llccc}
\hline Sub DAS & \multicolumn{1}{c}{ Lokasi } & $\begin{array}{c}\text { Luas Penampang } \\
\left(\mathrm{m}^{2}\right)\end{array}$ & $\begin{array}{c}\text { Kecepatan } \\
\text { Aliran }(\mathrm{m} / \mathrm{s})\end{array}$ & $\begin{array}{c}\text { Debit } \\
\left(\mathrm{m}^{3} / \mathrm{s}\right)\end{array}$ \\
\hline Buluh & Kelurahan Koto Panjang & 11,48 & 0,26 & 2,98 \\
\hline Lembang & Nagari Salayo & 13,76 & 0,24 & 3,4 \\
\hline Cupak & Nagari Koto Baru & 12 & 0,28 & 3,36 \\
\hline Lubuk Salasih & Nagari Koto Baru & 13,05 & 0,32 & 4,2 \\
\hline
\end{tabular}

Sumber : Pengolahan data primer (2017) 


\section{Kapasitas Tampung Sungai}

Kapasitas tampung sungai diperoleh dengan membandingkan hasil perhitungan debit banjir maksimum dengan metode rasional dengan debit sungai (Megawati,
2005). Kapasitas tampung sungai dapat ditentukan dengan menggunakan metode yang sama dengan debit sungai tetapi menggunakan data tinggi sungai bukan tinggi muka air.

Tabel 9. Kapasitas Tampung Sungai Sub DAS Buluh, Sub DAS Lembang

\begin{tabular}{|c|c|c|c|c|}
\hline Sub DAS & Lokasi & $\begin{array}{c}\text { Luas } \\
\text { Penampang } \\
\left(\mathrm{m}^{2}\right)\end{array}$ & $\begin{array}{c}\text { Kecepatan } \\
\text { Aliran } \\
(\mathrm{m} / \mathrm{s})\end{array}$ & $\begin{array}{c}\text { Kapasitas } \\
\text { tampung } \\
\left(\mathrm{m}^{3} / \mathrm{s}\right)\end{array}$ \\
\hline Buluh & $\begin{array}{l}\text { Kelurahan } \\
\text { Koto } \\
\text { Panjang }\end{array}$ & 28,7 & 0,26 & 7,46 \\
\hline Lembang & $\begin{array}{l}\text { Nagari } \\
\text { Salayo }\end{array}$ & 22,36 & 0,24 & 5,26 \\
\hline Cupak & $\begin{array}{l}\text { Nagari } \\
\text { Koto Baru }\end{array}$ & 21 & 0,28 & 5,88 \\
\hline $\begin{array}{l}\text { Lubuk } \\
\text { Selasih }\end{array}$ & $\begin{array}{l}\text { Nagari } \\
\text { Koto Baru }\end{array}$ & 21,75 & 0,32 & 6,96 \\
\hline \multicolumn{4}{|c|}{ Rata-rata } & 6,39 \\
\hline
\end{tabular}

Sumber :Pengolahan data primer 2017

Sungai pada Sub DAS Lubuk Selasih memiliki kapasitas tampung paling besar dibandingkan empat sub DAS lainnya karena luas penampangnya yang besar dan aliran yang cepat. Debit banjir maksimum, Sub DAS Lubuk Selasih mempunyai sebesar $60,8 \mathrm{~m}^{3} / \mathrm{s}$ dan merupakan debit terbesar dibandingkan tiga sub DAS lainnya. Perbandingan antara debit banjir maksimum pada Sub DAS Lubuk Selasih dengan besar kapasitas sungai, mengindikasikan akan terjadi banjir kemungkinan sekali dalam periode ulang dua tahun dengan besar $53,84 \mathrm{~m}^{3} / \mathrm{s}$.

Kapasitas tampung sungai pada tahun sebelumnya diperhitungkan karena banjir juga terjadi pada tahun sebelum 2017 berdasarkan data informasi bencana Indonesia menurut BNPB. Kapasitas tampung sungai pada tahun sebelumnya dapat diperkirakan dengan menggunakan data debit sungai dan tinggi muka air yang diperoleh dari Dinas Pengelolaan Sumber Daya Air (PSDA) Sumbar. Dari data debit dan tinggi muka air, dapat diketahui kecepatan aliran air.

4. Pengaruh Kapasitas Tampung Sungai Terhadap Ketinggian Banjir DAS Sumani

Untuk mengetahui pengaruh kapasitas tampung sungai terhadap banjir maka dilakukan analisis statistik regresi linear sederhana. Kapasitas tampung sungai ditetapkan sebagai variabel bebas (independent variabel) yang dilambangkan dengan $X$. Sedangkan banjir merupakan variabel terikat (dependent variabel) yang dilambangkan dengan Y. Data variabel terikat menggunakan data yang sudah ada berupa ketinggian banjir pada titik prngambilan sampel. Pengolahan regresi linear sederhana dilakukan dengan menggunakan software SPSS 16.0.

Hasil perhitungan untuk nilai koefisien korelasi adalah -0,832 yang berarti terjadi hubungan korelasi negatif antara variabel $\mathrm{X}$ dengan variabel $\mathrm{Y}$ yang diteliti. Korelasi negatif berarti, jika satu variabel mengalami peningkatan, variabel 
lain akan mengalami penurunan. Jika kapasitas tampung pada DAS bertambah, maka ketinggian banjir akan berkurang. Nilai koefisien korelasi memiliki nilai 0,832 yang berarti memiliki korelasi yang tinggi atau kuat.

Persamaan regresi linear sederhana pada penelitian ini sebagai berikut:

$$
\begin{gathered}
Y=a+b X \\
Y=9,548-0,634 X
\end{gathered}
$$

Setiap penambahan $1 \mathrm{~m}^{3} / \mathrm{s}$ nilai variabel $\mathrm{X}$ atau kapasitas sungai maka akan terjadi pengurangan 0,634 variabel $\mathrm{Y}$ atau ketinggian banjir pada Batang Sumani Solok.

\section{KESIMPULAN DAN SARAN}

\section{Kesimpulan}

a. DAS Sumani yang dibagi menjadi empat sub DAS memiliki Debit banjir maksimum masing-masing sebagai berikut: Sub DAS Buluh memiliki debit sebesar $7,51 \mathrm{~m}^{3} / \mathrm{s}$ (detik) pada dua tahun mendatang, Sub DAS Lembang memiliki debit sebesar $48,01 \mathrm{~m}^{3} / \mathrm{s}$ pada dua tahun mendatang, Sub DAS Cupak memiliki debit sebesar $55,76 \mathrm{~m}^{3} / \mathrm{s}$ pada dua tahun mendatang dan Sub DAS Lubuk Selasih memiliki debit sebesar $60,8 \mathrm{~m}^{3} / \mathrm{s}$ pada dua tahun mendatang.

b. Debit sungai pada Sub DAS Buluh yang diukur di Kelurahan Koto Panjang adalah sebesar 2,98 $\mathrm{m}^{3} / \mathrm{s}$, Debit sungai pada Sub DAS Lembang yang diukur di Nagari Salayo adalah sebesar $3,4 \mathrm{~m}^{3} / \mathrm{s}$, Debit sungai pada Sub DAS Cupak yang diukur di Nagari Koto Baru adalah sebesar 3,36 $\mathrm{m}^{3} / \mathrm{s}$ dan Debit sungai pada Sub DAS Lubuk Selasih adalah sebesar $4,2 \mathrm{~m}^{3} / \mathrm{s}$. Total debit DAS Sumani adalah sebesar $13,8 \mathrm{~m}^{3} / \mathrm{s}$

c. Kapasitas tampung sungai pada Sub DAS Buluh adalah sebesar 7,46 $\mathrm{m}^{3} / \mathrm{s}$ dan pada dua tahun mendatang kapasitas masih tersedia sebesar 0,05 $\mathrm{m}^{3} / \mathrm{s}$. Kapasitas tampung sungai pada Sub DAS Lembang adalah sebesar 5,26 $\mathrm{m}^{3} / \mathrm{s}$ dan pada dua tahun mendatang akan melebihi kapasitas sebesar 42,75 $\mathrm{m}^{3} / \mathrm{s}$. Kapasitas tampung sungai pada Sub DAS Cupak adalah sebesar 5,88 $\mathrm{m}^{3} / \mathrm{s}$ dan pada dua tahun mendatang akan melebihi kapasitas sebesar 49,88 $\mathrm{m}^{3} / \mathrm{s}$. Kapasitas tampung sungai pada Sub DAS Lubuk Selasih adalah sebesar $6,96 \mathrm{~m}^{3} / \mathrm{s}$ dan pada dua tahun mendatang akan melebihi kapasitas sebesar 53,84 $\mathrm{m}^{3} / \mathrm{s}$. Kapasitas tampung sungai rata-rata pada DAS Sumani pada tahun 2017 adalah $6,39 \mathrm{~m}^{3} / \mathrm{s}$.

d. Pengaruh kapasitas tampung sungai terhadap banjir pada DAS Sumani adalah memiliki pengaruh negatif dengan angka koefisien korelasi 0,832. Jika kapasitas tampung sungai meningkat, maka ketinggian banjir akan berkurang. Setiap penambahan $1 \mathrm{~m}^{3} / \mathrm{s}$ dari nilai kapasitas tampung sungai maka nilai ketinggian banjir akan berkurang $0,634 \mathrm{~cm}$.

\section{Saran}

a. Untuk pemerintah terutama bagian pengelolaan air agar lebih memperhatikan kondisi sungai misalnya dengan menempuh upaya pengerukan terhadap sungai agar dapat menampung debit air dengan maksimal karena banjir yang terjadi pada DAS Sumani dipengaruhi oleh kapasitas tampung sungai dalam menampung debit sungai. Tindakan konservasi DAS perlu dilakukan di sepanjang Batang Sumani, misalnya dengan menambah ketersediaan ruang terbuka hijau disepanjang Batang Sumani agar daya 
serap air hujan dapat lebih optimal terutama disepanjang aliran sungai.

b. Untuk masyarakat diharapkan agar berpartisipasi dalam menjaga kelestarian sungai misalnya dengan tidak membuang sampah ke sungai.

c. Metode yang dipakai dalam penelitian ini tidak menerangkan pengaruh sedimentasi terhadap kapasitas tampung sungai, untuk peneliti selanjutnya diharapkan dapat mempertimbangkan faktor tersebut.

\section{DAFTAR RUJUKAN}

Asdak, C. (2010). Hidrologi dan Pengelolaan Daerah Aliran Sungai. Yogyakarta: Gadjah Mada University Press.

Darmanto. (2007). Pengelolaan Air yang Berkelanjutan berdasarkan Banjir dan Kekeringan sebagai Faktor Penentu Daya Dukung Lahan. Jurnal Teknik Pengelolaan Bencana Alam , 2-3.

Fokusriau. (2014, November 2014). Pemkab Solok evakuasi dan salurkan bantuan korban banjir. Retrieved Februari 10, 2017, from Fokusriau:http://fokusriau.com/beritapemkab-solok-evakuasi-dan-salurkan-bantuan-korban-banjir-.html

Haluan. (2017, Januari 5). Sungai Batang Lembang Meluap, Ratusan Rumah di Kabupaten Solok dan Kota Solok Terendam Banjir di Kabupaten Solok. Retrieved januari 8, 2017, from Haluan: http://harianhaluan.-com/news/sungai-batang-lembang-meluapratusan-rumah-di-kabu-paten-solok-dan-kota-solok-ter-endam-banjir.

Kodoatie, R. J. (2002). Banjir. Yogyakarta: Pustaka Pelajar

Megawati, Y. M. (2005). Evaluasi Kapasitas Tampung Maksimum Sungai dan saluran drainase terhadap Banjir Maksimum (Studi Kasus DAS Way Kuala Garuntang Bandar Lampung). Jurnal Teknik Pertanian Universitas Lampung , 5.

Republik Indonesia. 2007. Peraturan Pemerintah Republik Indonesia nomor 24 Tahun 2007 tentang Penanggulangan Bencana.. Lembaga Negara RI tahun 2007. Jakarta : Kementerian Sekretariat Negara

Soewarno. (2014). Aplikasi Metode Statistika untuk Analisis Data Hidrologi. Yogyakarta: Graha Ilmu.

Widodo, T. (2014). Tingkat kerentanan bencana banjirsungai Citarum di Kecamatan Batujaya Kabupaten Karawang. Jurnal UPI , 1 